\title{
Lower expressions of the human bitter taste receptor TAS2R in smokers: reverse transcriptase-polymerase chain reaction analysis
}

Mieko Aoki ${ }^{*}$, Tetsuya Takao ${ }^{2}$, Kyoichi Takao ${ }^{3}$, Fumihiko Koike ${ }^{4}$ and Narufumi Suganuma ${ }^{5}$

\begin{abstract}
Background: Despite the fact that smokers have deficit in detecting taste, particularly bitter taste, no study has investigated its biological correlate.

Methods: In this context, we compared the expression of the bitter taste receptor gene, taste 2 receptor (TAS2R) in the tongues of smokers and non-smokers. Tissue samples were collected from the lateral portion of the tongues of 22 smokers and 22 age- and gender-matched healthy volunteers (19 males and three females) with no history of smoking. Reverse transcriptase-polymerase chain reaction was used to examine the expression of TAS2R in the two groups, and the effect of aging on TAS2R expression was also assessed.
\end{abstract}

Results: TAS2R expression was significantly lower among smokers than non-smokers ( $t=6.525, P<.0001,11.36 \pm 6.0$ vs. $2.09 \pm 2.8$, mean $\pm S D$, non-smokers vs. smokers). Further, a positive correlation between age and expression of TAS2R was observed in non-smokers ( $r=.642, P=.001)$, but not smokers $(r=.124, P=.584)$. This correlation difference was significant $(Z=1.96, P=.0496)$.

Conclusions: Smokers showed a significantly lower expression of the bitter taste receptor gene than non-smokers, which is potentially caused by their inability to acquire such receptors with age because of cigarette smoking, in contrast to non-smokers.

Keywords: Cigarette, Human, TAS2R, RT-PCR

\section{Background}

Accumulating evidence has demonstrated that cigarette smoking induces non-critical adverse effects [1-5] in addition to the well-established critical adverse effects such as the development of cancers and coronary artery diseases [6,7]. Among the non-critical adverse effects of smoking, bitter taste impairment is particularly important in the field of public health [8-11], not only because it affects the quality of life of smokers but also because it may promote the continuation of smoking which will eventually cause critical adverse effects in both smokers and their relatives. However, despite the importance of this as a potential mechanism for the continuation of smoking [12-14], to the best of our knowledge no study

\footnotetext{
* Correspondence: myaoki@sguc.ac.jp

${ }^{1}$ Department of food and nutrition, Sanyo Gakuen College, 1-14-1 Hirai, Naka-ward, Okayama 703-8501, Japan

Full list of author information is available at the end of the article
}

has investigated the biological mechanism of this bitter taste disability.

Bitter tastes are perceived by taste receptor cells (TRC) which are assembled into taste buds [15]. In humans, TRCs detect bitter stimuli via a bitter taste receptor, the taste 2 receptor (TAS2R) G-protein-coupled receptor (GPCR) [15]. Although their roles have yet to be elucidated, human genome studies have shown that the TRC-expressed GPCR multi-gene family consists of 25 T2R members [16]. They are named by adding numbers at the end, such as TAS2R1 or TAS2R3.

There are some studies that suggested potential genetic effect of smoking cigarette, such as association between smoking cigarettes and SNP expression [17]. We hypothesized that cigarette smoking induces a lower expression of TAS2R in smokers compared with nonsmokers. To test this, we performed reverse transcriptase- 
polymerase chain reaction (RT-PCR) analysis of TAS2R expression in tongue tissue samples of both groups.

\section{Methods}

\section{Participants and clinical evaluation}

Twenty-two smokers (20 males and two females) with no history of taste disorders were recruited to participate in the study. They are mainly college students and acquaintances of the authors. The following information was obtained from each of these participants: age (years), smoking duration (years), and the number of cigarettes smoked per day; these data were also used to determine the Brinkman index, which is defined as the number of cigarettes smoked daily multiplied by the number of smoking years. Twenty-two age- and gender-matched healthy volunteers (19 males and three females) with no history of smoking were employed as controls. To avoid age-associated loss of expression, we excluded participants aged 65 years or over from both groups.

The ethics committee of Sanyo Gakuen College, Showa women's University and Medical school of Nihon University approved the current study. After a complete explanation of the study to the subjects, written informed consent was obtained from every participant.

\section{Sample collection}

We adopted a scraping method to collect tissue samples for this study because it was difficult to perform an excisional biopsy in several cases. This scraping method is so minimally invasive that it is often used to collect tissue samples from the oral cavity. We considered it suitable as a tissuesampling method in the present study for the examination of taste receptor gene expression of the tongue. Thus, by scraping with plastic tube, we obtain the epithelium specimen from tip, dorsum and foliate papilla in the tongue. None of the participants had anything to eat or drink for at least $90 \mathrm{~min}$ before scraping the tongue surface. The specimens were vortexed with TRIzol Reagent (Invitrogen) of $0.5 \mathrm{ml}$ for 30 seconds. Then, upper aqueous phase was transferred carefully into fresh tube without disturbing the interphase and used as specimens of interest. The lower red phenol-chloroform phase was used for assessment of potential contamination of DNA. Specimens were refrigerated at temperature of $-5^{\circ} \mathrm{C}$ for a night then $-35^{\circ} \mathrm{C}$ for a few days before RT-PCR. Based on the instruction of TRIzol Reagent, all RNAs were purified from the specimen. To make sample to be suitable for RT-PCR, the pellet of total RNA was dissolved in DEPC-treated water of $10 \mu \mathrm{L}$. The concentration of total RNA in the sample was measured. The sample was stored at temperature of $-80^{\circ} \mathrm{C}$.

\section{Reverse transcriptase-polymerase chain reaction}

RT-PCR was performed as previously described [18]. Briefly, the primer pairs (Table 1) were designed from 5' sides and 3' sides of TAS2R genes. Using SuperScript III (Invitrogen, Carlsbad, CA, USA) and random primers (Invitrogen, Carlsbad, CA, USA), first strand cDNAs were reverse-transcribed from $0.65 \mu \mathrm{g}$ total RNA. The cDNA of $0.5 \mu \mathrm{L}$ was used as a template for PCR reaction. The PCR was performed with ExTaq (Takara Bio Inc., Shiga, Japan). The PCR amplification was started with a denaturation step at $95^{\circ} \mathrm{C}$ for $5 \mathrm{~min}$ followed by 35 cycles consisting of denaturation $\left(95^{\circ} \mathrm{C}\right.$ for $\left.30 \mathrm{sec}\right)$, annealing $\left(59^{\circ} \mathrm{C}\right.$ for $\left.30 \mathrm{sec}\right)$ and extension $\left(72^{\circ} \mathrm{C}\right.$ for $\left.60 \mathrm{sec}\right)$. The oligonucleotides used for TAS2R amplification is shown in Table 1. The sample was incubated for seven minutes at $72^{\circ} \mathrm{C}$. After PCR reaction, the specimen was stored at $4^{\circ} \mathrm{C}$. The length and amount of PCR product was analyzed using 2100 Agilent Bioanalyzer (Agilent Technology, Tokyo, Japan) with 7500 Agilent DNA Reagent.

\section{Assessment of potential contamination of DNA}

After ethanol precipitation of the lower red phenolchloroform phase of the specimen, genomic DNA was extracted. Then, extracted genomic DNA was analyzed by agarose gel electrophoresis.

\section{Statistical analyses}

Independent $t$-tests were performed to compare the differences in age between smokers and non-smokers, and in the expression of the bitter taste receptor gene TAS2R between smokers and non-smokers. Statistical significance was set at $P<.05$.

Independent $t$-tests were also performed to compare the difference in the expression of TAS2R subfamily genes between smokers and non-smokers. Because we had no a priori hypothesis for potential expression level differences in the TAS2R subfamily, statistical significance was set at $P<.0024$ ( $=.05 / 21$, number of TAS2R subfamily members successfully measured), correcting multiple comparisons using Bonferroni method.

\section{Correlation analysis}

To explore the potential effect of age on the expression of bitter taste receptor genes, we performed Pearson's correlation analyses between age and TAS2R expression in non-smokers and smokers separately. Differences in correlations between groups were examined with the Fisher r-to-z transformation [19]. The statistical threshold was set at $P<.05$.

Further, to examine the effect of potential factors related to bitter taste receptor gene expression among smokers, we conducted Pearson's correlation analyses between TAS2R expression and period of smoking (years), number of cigarettes smoked daily, and the Brinkman index. The statistical threshold was also set at $P<.05$. 
Table 1 List of the sequences of the oligonucleotides used for TAS2R amplification

\begin{tabular}{|c|c|c|c|c|}
\hline TAS2R & Accession number & Primer name & Primer & Product length \\
\hline \multirow[t]{2}{*}{ TAS2R1 } & NM_019599 & TAS2R1/F & atg cta gag tct cac ctc att atc & $900 \mathrm{bp}$ \\
\hline & & TAS2R1/R & tca ctg aca gca ctt act gtg gag g & \\
\hline \multirow[t]{2}{*}{ TAS2R3 } & NM_016943 & TAS2R3/F & atg atg gga ctc acc gag ggg g & $951 \mathrm{bp}$ \\
\hline & & TAS2R3/R & cta aga gaa aat ggg tcc ctt gg & \\
\hline \multirow[t]{2}{*}{ TAS2R4 } & NM_016944 & TAS2R4/F & atg ctt cgg tta ttc tat ttc & $900 \mathrm{bp}$ \\
\hline & & TAS2R4/R & cta ttt ttt gaa aca aag aat c & \\
\hline \multirow[t]{2}{*}{ TAS2R5 } & NM_018980 & TAS2R5/F & atg ctg agc gct ggc cta gga ctg & $900 \mathrm{bp}$ \\
\hline & & TAS2R5/R & tca tgg gec cca gca tct ccg agc & \\
\hline \multirow[t]{2}{*}{ TAS2R7 } & NM_023919 & $\mathrm{TAS} 2 \mathrm{R} 7 / \mathrm{F}$ & atg gca gat aaa gtg cag act ac & $957 \mathrm{bp}$ \\
\hline & & TAS2R7/R & tca gat ttg ttt atg ttg ttg ga & \\
\hline \multirow[t]{2}{*}{ TAS2R8 } & NM_023918 & TAS2R8/F & atg ttc agt cct gca gat aac & $930 \mathrm{bp}$ \\
\hline & & TAS2R8/R & tca tat cat gca ggc aat ttt tc & \\
\hline \multirow[t]{2}{*}{ TAS2R9 } & NM_023917 & TAS2R9/F & atg cca agt gca ata gag gc & $939 \mathrm{bp}$ \\
\hline & & TAS2R9/R & cta tgg aac aaa agg ctt tc & \\
\hline \multirow[t]{2}{*}{ TAS2R10 } & NM_023921 & TAS2R10/F & atg cta cgt gta gtg gaa ggc & $924 \mathrm{bp}$ \\
\hline & & TAS2R10/R & cta tgt gac tct gag att ttt cc & \\
\hline \multirow[t]{2}{*}{ TAS2R13 } & NM_023920 & TAS2R13/F & atg gaa agt gec ctg ccg ag & $912 \mathrm{bp}$ \\
\hline & & TAS2R13/R & tca tcg ttt agc cca tac c & \\
\hline \multirow[t]{2}{*}{ TAS2R14 } & NM_023922 & TAS2R14/F & atg ggt ggt gtc ata aag ag & $954 \mathrm{bp}$ \\
\hline & & TAS2R14/R & tca aga tga ttc tct aaa ttc & \\
\hline \multirow[t]{2}{*}{ TAS2R16 } & NM_016945 & TAS2R16/F & atg ata ccc atc caa ctc ac & $876 \mathrm{bp}$ \\
\hline & & TAS2R16/R & cta gca ctt tcc ctt & \\
\hline \multirow[t]{2}{*}{ TAS2R19 } & NM_176888 & TAS2R19/F & atg atg tgt ttt ctg ctc atc & $900 \mathrm{bp}$ \\
\hline & & TAS2R19/R & tca gcg tgt cat ctg cca caa a & \\
\hline \multirow[t]{2}{*}{ TAS2R20 } & NM176889 & TAS2R20/F & atg atg agt ttt cta cac att $\mathrm{g}$ & $930 \mathrm{bp}$ \\
\hline & & TAS2R20/R & cta tgg agt tga ctg gtt ctg tcc & \\
\hline \multirow[t]{2}{*}{ TAS2R30 } & NM_001097643 & TAS2R30/F & atg ata act ttt ctg $c c c$ atc a & $960 \mathrm{bp}$ \\
\hline & & TAS2R30/R & cta gaa gac aca caa tgc ccc tc & \\
\hline \multirow[t]{2}{*}{ TAS2R31 } & NM176885 & TAS2R31/F & atg aca act ttt ata ccc atc & $930 \mathrm{bp}$ \\
\hline & & TAS2R31/R & cta tgg aga tga agg ctt ctc tcc & \\
\hline \multirow[t]{2}{*}{ TAS2R38 } & NM_176817 & TAS2R38/F & atg ttg act cta act cgc atc & 1002 bp \\
\hline & & TAS2R38/R & tca gca cag tgt ccg gga atc $t$ & \\
\hline \multirow[t]{2}{*}{ TAS2R39 } & NM_176881 & TAS2R39/F & atg cta ggg aga tgt ttt cct cc & 1017 bp \\
\hline & & TAS2R39/R & tca cag agt cca ctc ttt tgg gt & \\
\hline \multirow[t]{2}{*}{ TAS2R40 } & NM_176882 & TAS2R40/F & atg gca acg gtg aac aca gat g & $972 \mathrm{bp}$ \\
\hline & & TAS2R40/R & tca cag agt ctg ccc ttt tag gt & \\
\hline \multirow[t]{2}{*}{ TAS2R42 } & NM_191429 & TAS2R42/F & atg gcc acc gaa ttg gac & $945 \mathrm{bp}$ \\
\hline & & TAS2R42/R & cta caa agg taa agg gtt tgg tg & \\
\hline \multirow[t]{2}{*}{ TAS2R43 } & NM176884 & TAS2R43/F & atg ata act ttt cta ccc atc & $930 \mathrm{bp}$ \\
\hline & & TAS2R43/R & cta tgg aga tga agt ctt ctc tcc & \\
\hline \multirow[t]{2}{*}{ TAS2R45 } & NM_176886 & TAS2R45/F & atg ata act ttt ctg ccc atc & $900 \mathrm{bp}$ \\
\hline & & TAS2R45/R & tca gta cct cat ttg cca caa aac tg & \\
\hline
\end{tabular}




\section{Results}

\section{Demographic characteristics}

There was no significant difference in the age of the participants between the smokers and non-smokers $(46.0 \pm 11.4$ years (mean $\pm \mathrm{SD}$; range, 23-65) and $41.5 \pm$ 15.8 years (mean \pm SD; range, 23-65), respectively; $P=.290$ ) (Table 2). The mean duration of smoking was $24.3 \pm 9.7$ years (mean \pm SD), and an average of $17.4 \pm 7.0$ cigarettes were smoked daily (mean $\pm \mathrm{SD}$ ). Consequently, the mean Brinkman index was $430.0 \pm 246.7$ (mean \pm SD) in smokers (Table 2).

\section{Assessment of potential contamination of DNA}

As shown in Figure 1, genomic DNAs were fragmented into less than 200bp.

\section{Comparison of TAS2R expression between smokers and non-smokers}

The mean expression of TAS2R in smokers and nonsmokers was 2.09 and 11.36, respectively. This difference was statistically significant, with smokers having a significantly lower TAS2R expression compared with non-smokers $(t=6.525, P<.0001$, Table 3$)$.

\section{Comparison of TAS2R subfamily expression}

Independent $t$-tests revealed that the expression of five members of the TAS2R subfamily was significantly lower among smokers compared with non-smokers. These members are: TAS2R7 $(t=3.928, P=.0003, .64 \pm .49$ vs. $.09 \pm .43$, mean \pm SD, non-smokers $v$. smokers), TAS2R9 $(t=3.391, P=.0011, .82 \pm .39$ vs. $.32 \pm .57$, mean $\pm \mathrm{SD}$, non-smokers v. smokers), TAS2R30 $(t=7.483, P<.0001$, $.73 \pm .46$ vs. $0 \pm 0$, mean $\pm S D$, non-smokers v. smokers), TAS2R38 $(t=5.508, \quad P<.0001, .59 \pm .50 \quad$ vs. $0 \pm 0$, mean \pm SD, non-smokers v. smokers), and TAS2R45 $(t=4.583, \quad P<.0001, .50 \pm .51$ vs. $0 \pm 0$, mean $\pm \mathrm{SD}$, non-smokers v. smokers) (Table 2). Although it did not reach significance, the mean expression of TAS2R4 was higher among smokers $(.32 \pm .48$, mean \pm SD) than non-smokers $(.36 \pm .73$, mean $\pm \mathrm{SD})(P=.108$; Table 2$)$.

Table 2 Demographic characteristics of participants

\begin{tabular}{|c|c|c|c|c|c|c|}
\hline \multirow[t]{2}{*}{ Variable } & \multicolumn{2}{|c|}{$\begin{array}{c}\text { Non-smoker } \\
(n=22) \\
\end{array}$} & \multicolumn{2}{|c|}{$\begin{array}{l}\text { Smoker } \\
(n=22)\end{array}$} & \multicolumn{2}{|c|}{$t$-test } \\
\hline & Mean & SD & Mean & SD & $t$-value & $P$-value \\
\hline Age (years) & 41.5 & 15.8 & 46.0 & 11.4 & 1.1 & .290 \\
\hline $\begin{array}{l}\text { Duration of smoking } \\
\text { (years) }\end{array}$ & NA & NA & 24.3 & 9.7 & NA & NA \\
\hline $\begin{array}{l}\text { Number of cigarettes } \\
\text { smoked daily }\end{array}$ & NA & NA & 17.4 & 7.0 & NA & NA \\
\hline Brinkman index & NA & NA & 430 & 246.7 & NA & NA \\
\hline
\end{tabular}

Abbreviations: NA, not applicable; SD, standard deviation.

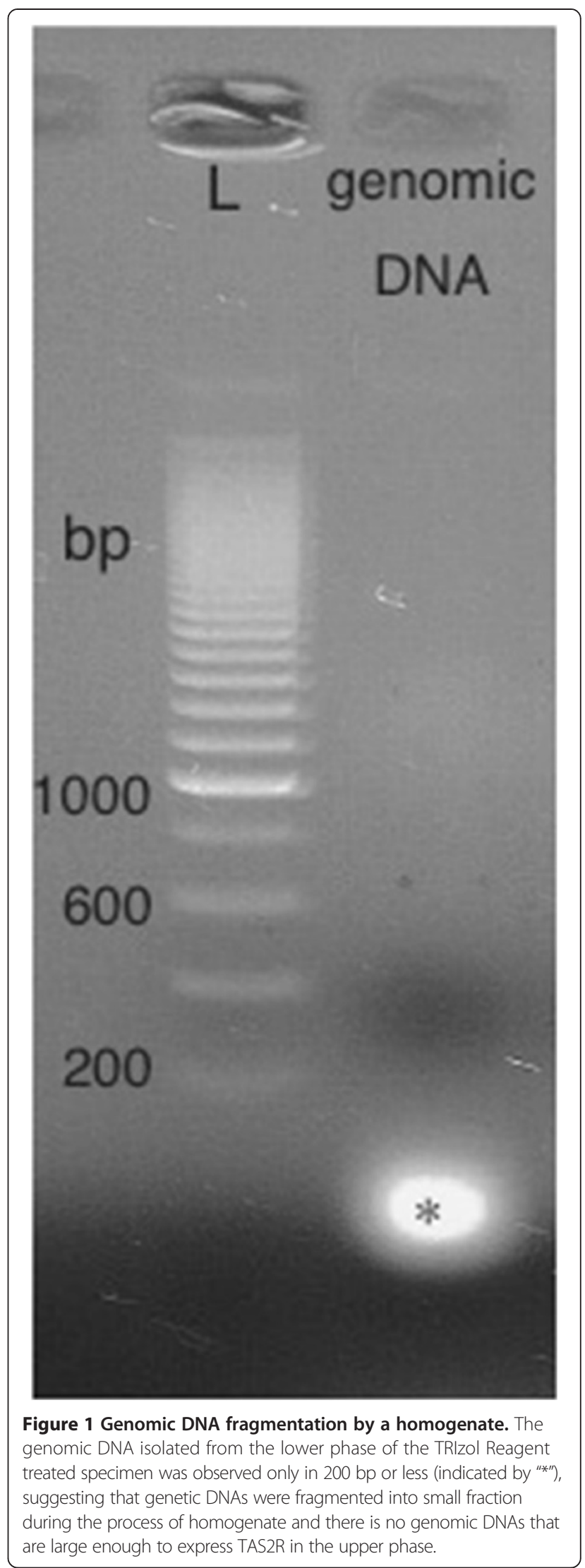


Table 3 Mean age and expression of TAS2R and its subfamily

\begin{tabular}{|c|c|c|c|c|c|c|c|}
\hline \multirow[t]{2}{*}{ Variable } & \multicolumn{2}{|c|}{ Non-smoker $(n=22)$} & \multicolumn{2}{|c|}{ Smoker $(n=22)$} & \multicolumn{3}{|c|}{ Independent $t$-tests } \\
\hline & Mean & SD & Mean & SD & $t$-value & df & $P$-value \\
\hline Total TAS2R expression & 11.36 & 6.04 & 2.09 & 2.81 & 6.525 & 42 & $<.0001^{*}$ \\
\hline \multicolumn{8}{|l|}{ TAS2R subfamily expression } \\
\hline TAS2R1 & .55 & .51 & .18 & .59 & 2.191 & 42 & .0341 \\
\hline TAS2R3 & .68 & .48 & .45 & .67 & 1.295 & 42 & .2024 \\
\hline TAS2R4 & .32 & .48 & .36 & .73 & .25 & 42 & .8074 \\
\hline TAS2R5 & .36 & .49 & .27 & .70 & .50 & 42 & .6217 \\
\hline TAS2R7 & .64 & .49 & .09 & .43 & 3.928 & 42 & $.0003^{*}$ \\
\hline TAS2R8 & .82 & .39 & .55 & .67 & 1.643 & 42 & .1078 \\
\hline TAS2R9 & .82 & .39 & .32 & .57 & 3.391 & 42 & $.0011^{*}$ \\
\hline TAS2R10 & .77 & .43 & .36 & .58 & 2.657 & 42 & .0111 \\
\hline TAS2R13 & .45 & .51 & .18 & .59 & 1.643 & 42 & .1078 \\
\hline TAS2R14 & .36 & .49 & .32 & .57 & .28 & 42 & .7781 \\
\hline TAS2R16 & .64 & .49 & .27 & .46 & 2.542 & 42 & .0148 \\
\hline TAS2R19 & .59 & .50 & .14 & .47 & 3.104 & 42 & .0034 \\
\hline TAS2R20 & .27 & .46 & 0 & 0 & 2.806 & 42 & .0076 \\
\hline TAS2R30 & .73 & .46 & 0 & 0 & 7.483 & 42 & $<.0001^{*}$ \\
\hline TAS2R31 & .27 & .46 & 0 & 0 & 2.806 & 42 & .0076 \\
\hline TAS2R38 & .59 & .50 & 0 & 0 & 5.508 & 42 & $<.0001^{*}$ \\
\hline TAS2R39 & .55 & .51 & .18 & .50 & 2.386 & 42 & .0216 \\
\hline TAS2R40 & .64 & .49 & .36 & .73 & 1.457 & 42 & .1525 \\
\hline TAS2R42 & .23 & .43 & 0 & 0 & 2.485 & 42 & .0170 \\
\hline TAS2R43 & .41 & .50 & .14 & .47 & 1.862 & 42 & .0696 \\
\hline TAS2R45 & .50 & .51 & 0 & 0 & 4.583 & 42 & $<.0001^{*}$ \\
\hline
\end{tabular}

*significant after Bonferroni correction.

\section{Correlation analyses}

Age was significantly positively correlated with the expression of TAS2R in the non-smoker group $(r=.642$, $P=.001)$ but not in the smoker group $(r=.124, P=.584)$ (Figure 2a). Fisher's r-to-z transformation revealed a significant difference in the correlations between the smokers and non-smokers $(Z=1.96, P=.0496)$, indicating that the age-expression of bitter taste receptor relationship in smokers was significantly different from that of non-smokers (Figure 2a).

Pearson's correlation analyses found no significant association between TAS2R expression and duration of smoking $(r=.217, P=.331)$ (Figure $2 \mathrm{~b})$, number of cigarettes smoked daily $(r=-.105, P=.641)$ (Figure 2c), or the Brinkman index $(r=.104, P=.645)$ (Figure 2c).

\section{Discussion}

In the current study, we detected a significantly lower expression of TAS2R in smokers compared with age- and gender-matched non-smokers. Sub-analyses also demonstrated that bitter taste receptor gene expression was significantly lower in five of the 21 receptors studied, TAS2R7, 9, 30 38, and 45. Although we did not investigate whether the current smokers have impaired taste, our results strongly suggest that the well-documented disturbance of taste seen in smokers derives from the lower-than-normal expression of TAS2R caused by smoking [8-11]. There are several potential substances that may affect the expression of TAS2R, the most potentially relevant of which is nicotine [20]. Indeed, previous studies have reported that nicotine decreased the expression of several genes [21,22]. Moreover, nicotine is known to induce the development of various cancers by causing DNA damage [23].

We also demonstrated that age-related changes in the expression of bitter taste receptors in smokers were significantly different from those in non-smokers, which is indicative of the potential accumulative effects of smoking. Although the association between age and the expression of bitter taste receptors is controversial and the relationship may not be consistent [24], it was reported to be greatly influenced by various environmental factors [25]. For instance, we previously reported that bitter taste receptor expression was influenced by exposure to a wide 


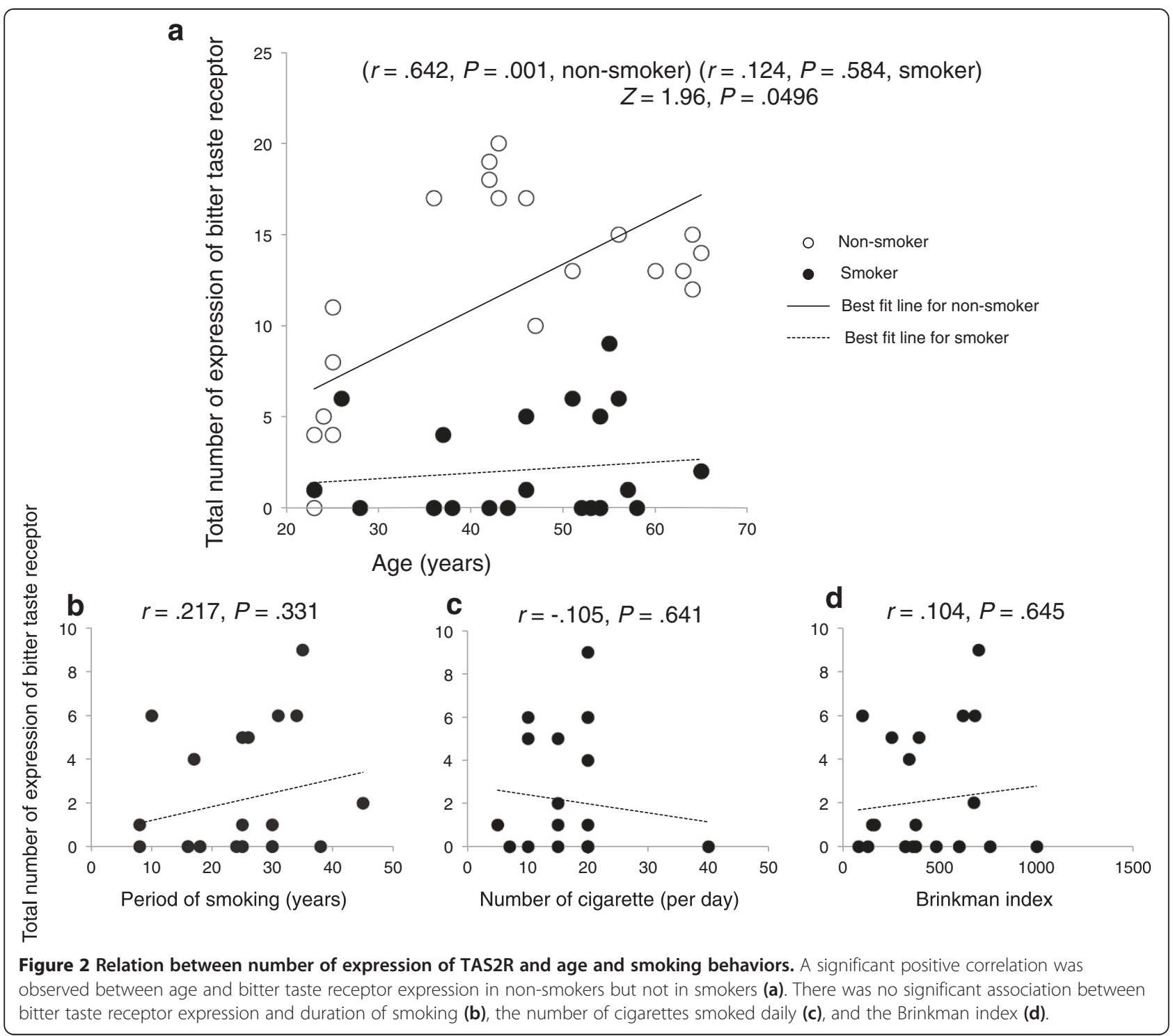

variety of foods; in other words the more food types people experience, the greater their expression of bitter taste receptors (presented at $15^{\text {th }}$ International Symposium on Olfaction and Taste at San Francisco). In the present study, we only included participants under 65 years of age. Thus, although additional factors might affect the relationship between age and bitter taste receptor expression, our results suggests that cigarette smoking impairs the acquisition of bitter taste receptors that occurs with aging and exposure to more tastes.

We observed no significant association between bitter taste receptor expression and smoking history, such as its duration and the number of cigarettes smoked daily. A possible explanation for this is that the expression of bitter taste receptors is so sensitive to environmental factors that it is conceivable that the expression would decrease to zero very quickly [25].
The current investigation has a number of methodological limitations. First, although we enlisted an age- and gender-matched non-smoker comparison group, several potential confounding factors were not considered that may affect TAS2R expression, such as genetic variability. Second, although this control group had no history of smoking, the potential effect of secondhand smoke was not investigated. However, unlike smoking, secondhand smoke does not enter the oral cavity, so its effect on TAS2R expression is potentially limited. Moreover, we mainly recruited adult males as the control group, and the Japanese Ministry of Health, Labour and Welfare reported that the prevalence of smoking among females is very low if their husbands do not smoke. Thus, although this should have been confirmed directly by questionnaire, the likelihood of exposure to secondhand smoke in our control group was low. Third, we 
did not investigate the mechanism by which cigarette smoke affects TAS2R expression, but it is assumed that there is a biochemical pathway that nicotine interferes with that decreases TAS2R expression. Fourth, although we have collected samples from the foliate papillae of the lateral portion of the tongue which is assumed to express bitter taste receptor well, and adopted standard method of the RT-PCR, no controls for presence of taste bud material for the RT-PCR experiments were performed. As it is state-of-the-art to perform and show control reaction such as samples amplified from not incubated with reverse transcription, further studies that adopted such method to improve the quality and reliability of the data are expected. Fifth, although we have shown that the lower phase of the TRIzol Reagent treated specimen included only genomic DNA fragments whose sizes are less than 200bp, suggesting that genomic DNA was fragmented into small factions by a process of homogenate we have not conducted enzymatic treatment of DNA degrading. Thus, there still remains possibility that the result of the present study is influenced by genomic DNA contamination. Sixth, although experimenter tried to obtain samples from tongue in the same manner in every participant, it may be rational criticism that the tongues of smokers and non-smokers are different in tissue. Concretely, it may be possible that the epithelium may be more keratinized in smokers than non-smokers, provoking the possibility that the difference in TAS2R expression between smokers and non-smokers derives from the difference in degree of keratinization rather than expression of the receptors. Similarly, the relation between smoking history and number of TAS2R expression may possibly reflect the effect of cigarette on lingual epithelium over years, rather than the mechanism we have assumed in the section of discussion. Further, although there was aging effect of number of expression of TAS2R among non-smoker between age of 20 and 65, it should be noted that such kind of aging effect may not continue after age of 65 .

There remain some unanswered questions. For example, we were unable to examine the temporal relationship between smoking and TAS2R expression. It would be interesting to determine which receptor decreases its expression after the beginning of smoking. Additionally, it is not clear whether TAS2R expression recovers after smoking abstinence. Future research should investigate these areas.

\section{Conclusions}

The current study demonstrated a significantly lower expression of the bitter taste receptor gene TAS2R in individuals who smoke cigarettes compared with non-smokers. Further, cigarette smoking may impede the acquisition of bitter taste receptors that occurs with experience.

\section{Abbreviations}

GPCR: G-protein-coupled receptor; RT-PCR: Reverse transcriptase-polymerase chain reaction; TAS2R: Taste 2 receptor; TRC: Taste receptor cells.

\section{Competing interests}

The authors declare that they have no competing interests.

\section{Authors' contribution}

MA designed the study. $\Pi$ and TK performed experiments. MA recruited participants. MA analyzed data and wrote the paper. TK and NS also took part in writing the paper. All authors read and approved the final manuscript.

\section{Author details}

${ }^{1}$ Department of food and nutrition, Sanyo Gakuen College, 1-14-1 Hirai, Naka-ward, Okayama 703-8501, Japan. ${ }^{2}$ Department of nutrition and health promotion, Showa Women's University, Tokyo, Japan. ${ }^{3}$ School of Medicine, Nihon University, Tokyo, Japan. ${ }^{4}$ Department of Dentistry and Oral Surgery, Nihon University, Tokyo, Japan. ${ }^{5}$ Department of Medicine, Kochi University, Kochi, Japan

Received: 3 June 2014 Accepted: 22 July 2014

Published: 15 August 2014

\section{References}

1. Spangler JG: Smoking and hormone-related disorders. Prim Care 1999, 26:499-511.

2. Cao S, Yin X, Wang Y, Zhou H, Song F, Lu Z: Smoking and risk of erectile dysfunction: systematic review of observational studies with meta-analysis. PLoS One 2013, 8:e60443.

3. Spechler SJ: Barrett esophagus and risk of esophageal cancer: a clinical review. JAMA 2013, 310:627-636.

4. Scott DL, Wolfe F, Huizinga TWJ: Rheumatoid arthritis. Lancet 2010, 376:1094-1108.

5. Gardener S, Gu Y, Rainey-Smith SR, Keogh JB, Clifton PM, Mathieson SL, Taddei K, Mondal A, Ward VK, Scarmeas N, Barnes M, Ellis KA, Head R, Masters CL, Ames D, Macaulay SL, Rowe CC, Szoeke C, Martins RN, AIBL Research Group: Adherence to a Mediterranean diet and Alzheimer's disease risk in an Australian population. Trans/ Psychiatry 2012, 2:e164.

6. Xue WQ, Qin HD, Ruan HL, Shugart YY, Jia WH: Quantitative association of tobacco smoking with the risk of nasopharyngeal carcinoma: a comprehensive meta-analysis of studies conducted between 1979 and 2011. Am J Epidemiol 2013, 178:325-338.

7. Fowkes F, Rudan D, Rudan I, Aboyans V, Denenberg J, McDermott M, Norman P, Sampson U, Williams L, Mensah G, Criqui M: Comparison of global estimates of prevalence and risk factors for peripheral artery disease in 2000 and 2010: a systematic review and analysis. Lancet 2013, 382:1329-1340.

8. Gromysz-Kałkowska K, Wójcik K, Szubartowska E, Unkiewicz-Winiarczyk A: Taste perception of cigarette smokers. Ann Univ Mariae Curie Sklodowska Med 2002, 57:143-154.

9. Raffaelli R, Baldinetti A, Somma F, Rumi G, Tiberi F: Variations in the taste function of smokers. Minerva Somatol 1989, 38:1253-1256.

10. Szejtli J, Szente L: Elimination of bitter, disgusting tastes of drugs and foods by cyclodextrins. Eur J Pharm Biopharm 2005, 61:115-125.

11. Mela D: Gustatory function and dietary habits in users and nonusers of smokeless tobacco. Am J CLin Nutr 1989, 49:482-489.

12. Enoch M, Harris C, Goldman D: Does a reduced sensitivity to bitter taste increase the risk of becoming nicotine addicted? Addict Behav 2001, 25:399-404

13. Cannon D, Baker T, Piper M, Scholand M, Lawrence D, Drayna D, McMahon W, Villegas G, Caton T, Coon H, MF L: Associations between phenylthiocarbamide gene polymorphisms and cigarette smoking. Nicotine Tob Res 2005, 7:853-858.

14. Snedecor S, Pomerleau C, Mehringer A, Ninowski R, Pomerleau O: Differences in smoking-related variables based on phenylthiocarbamide "taster" status. Addict Behav 2006, 31:2309-2312.

15. Maehashi K, Huang L: Bitter peptides and bitter taste receptors. Cell Mol Life Sci 2009, 66:1661-1671.

16. Brockhoff A, Behrens M, Niv MY, Meyerhof W: Structural requirements of bitter taste receptor activation. Proc Natl Acad Sci U S A 2010, 107:11110-5. 
17. Keller M, Liu X, Wohland T, Rohde K, Gast M, Stumvoll M, Kovacs P, Tönjes A, Böttcher Y: TAS2R38 and its influence on smoking behavior and glucose homeostasis in the German Sorbs. PLoS One 2013, 8:e80512.

18. Sekine H, Takao K, Yoshinaga K, Kokubun S, Ikeda M: Effects of zinc deficiency and supplementation on gene expression of bitter taste receptors (TAS2Rs) on the tongue in rats. Laryngoscope 2012, 122:2411-2417.

19. Meng YG, Liang J, Wong WL, Chisholm V: Green fluorescent protein as a second selectable marker for selection of high producing clones from transfected CHO cells. Gene 2000, 242:201-7.

20. Tomassini S, Cuoghi V, Catalani E, Casini G, Bigiani A: Long-term effects of nicotine on rat fungiform taste buds. Neuroscience 2007, 147:803-810.

21. Satta R, Maloku E, Zhubi A, Pibiri F, Hajos M, Costa E, Guidotti A: Nicotine decreases DNA methyltransferase 1 expression and glutamic acid decarboxylase 67 promoter methylation in GABAergic interneurons. Proc Natl Acad Sci U S A 2008, 105:16356-16361.

22. Shaykhiev R, Sackrowitz R, Fukui T, Zuo WL, Chao IW, Strulovici-Barel Y, Downey RJ, Crystal RG: Smoking-induced CXCL14 expression in the human airway epithelium links chronic obstructive pulmonary disease to lung cancer. Am J Respir Cell Mol Biol 2013, 49:418-425.

23. Hecht S: Cigarette smoking and lung cancer: chemical mechanisms and approaches to prevention. Lancet Oncol 2002, 3:461-469.

24. Winkler S, Garg A, Mekayarajjananonth T, Bakaeen L, Khan E: Depressed taste and smell in geriatric patients. J Am Dent Assoc 1999, 130:1759-1765.

25. Navarro-Allende A, Khataan N, El-Sohemy A: Impact of genetic and environmental determinants of taste with food preferences in older adults. J Nutr Elder 2008, 27:267-276.

doi:10.1186/1617-9625-12-12

Cite this article as: Aoki et al.: Lower expressions of the human bitter taste receptor TAS2R in smokers: reverse transcriptase-polymerase chain reaction analysis. Tobacco Induced Diseases 2014 12:12.

\section{Submit your next manuscript to BioMed Central and take full advantage of:}

- Convenient online submission

- Thorough peer review

- No space constraints or color figure charges

- Immediate publication on acceptance

- Inclusion in PubMed, CAS, Scopus and Google Scholar

- Research which is freely available for redistribution 